\title{
PENGEMBANGAN LABORATURIUM IPA DI BALAI DIKLAT KEAGAMAAN PALEMBANG
}

\section{Basuki M.Pd}

Balai Diklat Keagamaan Palembang

prabumulihbasuki@gmail.com

\begin{abstract}
Abstrak
Laboratorium IPA merupakan salahsatu wahana belajar peserta diklat dalam bidang IPA. Untuk menghasilkan proses belajar mengajar dan hasil belajar yang berkualitas, laboratorium harus dilengkapi dengan sarana dan prasarana yang diperlukan paling tidak sesuai dengan standar minimal sarana laboratorium. Untuk mengembangkan laboratorium di Balai Diklat Keagamaan Palembang diperlukan persyaratan umum laboratorium IPA, Persyaratan Laboratorium IPA, Tata Ruang Laboratorium IPA, serta personil laboratorium IPA.
\end{abstract}

Kata Kunci : Laboratorium IPA, Balai Diklat

\begin{abstract}
Science laboratory is one of the study participants training in the field of science .To produce the learning process and quality learning outcomes, must be equipped with laboratory facilities and infrastructure required at least in accordance with minimal standards laboratory facilities. To develop training center lab in religious palembang required the general requirements for laboratory science, the requirements of science laboratory, spatial science laboratory, and personnel science laboratory.
\end{abstract}

Keyword : science laboratory, training center 


\section{PENDAHULUAN}

Laboratorium IPA Di Balai Diklat Keagamaan Palembang merupakan salahsatu wahana belajar peserta diklat dalam bidang IPA. Untuk menghasilkan proses belajar mengajar dan hasil belajar yang berkualitas, laboratorium harus dilengkapi dengan sarana dan prasarana yang diperlukan paling tidak sesuai dengan standar minimal sarana laboratorium. Selain itu, personil laboratorium yang terdiri dari kepala laboratorium, teknisi, laboran, serta widyaiswara pembimbing praktikum juga harus mencerminkan tenaga berkualitas.

Laboratorium IPA di Balai Diklat Keagamaan Palembang perlu memperhatikan persyaratan umum laboratorium, sesuai dengan standar yang telah dikembangkan oleh BSNP. Dalam tulisan ini akan diuraikan bagaimana persyaratan yang dimaksud, yang sebelumnya diawali dengan kegiatan peran laboratorium IPA, persyaratan laboratorium IPA, Peralatan dan bahan di laboratorium IPA, personil yang terlibat dalam kegiatan laboratorium IPA, serta tata kelola laboratorium IPA IPA Balai Diklat Keagamaan Palembang.

\section{METODE PENELITIAN}

Penelitian ini menggunakan Metode deskriptif. Penelitian menggunakan Metode deskriptif adalah penelitian yang dilakukan untuk mengetahui nilai variable mandiri, baik satu variabel atau lebih (independent) tanpa membuat perbandingan, atau menghubungkan antara varibel yang satu dengan yang lain

\section{TEMUAN DAN PEMBAHASAN}

\section{Temuan}

Bagaimana mengembangkan Laboratorium IPA di Balai Diklat Keagamaan Palembang.

\section{Pembahasan}

1. Persyaratan Umum Laboratorium IPA

Laboratorium IPA merupakan salahsatu wahana belajar peserta diklat dalam bidang IPA. Untuk menghasilkan proses belajar mengajar dan hasil belajar yang berkualitas, laboratorium harus dilengkapi dengan sarana dan prasarana yang diperlukan paling tidak sesuai dengan standar minimal sarana laboratorium.

Menurut Standar Sarana dan Prasarana dari BNSP (2008), laboratorium IPA berfungsi sebagai tempat pembelajaran IPA secara praktek yang memerlukan peralatan khusus yang tidak mudah dihadirkan di kelas. Secara umum laboratorium dapat dimaknai sebagai tempat atau wahana yang dilengkapi dengan peralatan atau sarana pendukung yang diperlukan untuk melaksanakan kegiatan eksperimen, penelitian, pembuktian (verifikasi), dan pembelajaran. Dalam kaitannya dengan laboratorium IPA di Balai Diklat Keagamaan Palembang, laboratorium adalah suatu wahana yang dapat digunakan sebagai tempatbelajar selain di kelas, yang dilengkapi dengan peralatan dan bahanbahan yang diperlukan untuk pembelajaran IPA.

Kegiatan laboratorium IPA secara lebih jelas diungkapkan oleh Hodson (dalam Rosbiono,2003). Laboratorium sedikitnya mencakup empat kegiatan utama, yaitu (a) untuk melaksanakan eksperimen, (b). kerja laboratorium, (c). praktikum, dan (d) pelaksanaan didaktik pendidikan IPA.

Dari uraian di atas tampak, bahwa laboratorium IPA berperan penting baik untuk meningkatkan pemahaman terhadap konsep-konsep IPA, melatih keterampilan proses, maupun mengembangkan sikap ilmiah/positif peserta diklat. Kegiatan praktikum dengan verifikasi merupakan kegiatan praktikum yang paling sederhana, dan hanya mengembangkan sedikit keterampilan peserta diklat. Kegiatan 
praktikum dengan model inkuiri terbuka umumnya dilakukan berupa penugasan melalui kegiatan ilmiah. Praktikum denagn inkuiri terbuka sangat potensial mengembangkan semua potensi pada peserta diklat.

1. 2. Persyaratan Laboratorium IPA

Untuk dapat melaksanakan perannya sebagai wahana pendidikan selain di kelas, suatu laboratorium harus memiliki kelengkapan baik dalam hal tata bangunan dan fasilitas, peralatan, bahan, personil dan sistem tata kelola yang memadai. Selain itu, kelengkapan ini diperlukan untuk memastikan bahwa peserta dan personil yang bekerja di laboratorium terjamin keamanan dan keselamatannya.

Menurut Kemendiknas (2010) persyaratan laboratorium IPA sekolah meliputi dua aspek utama, yaitu :

1. Persyaratan teknis : terdiri atas persyaratan sarana dan prasarana, termasuk tata bangunan dan fasilitas, peralatan dan bahan, dan personil

2. Persyaratan manajemen (tata kelola): terdiri atas berbagai aspek seperti struktur organisasi, sistem mutu, dokumentasi/administrasi, serta sistem monitoring dan evaluasi.

3. Tata Bangunan dan Fasilitas Laboratorium

Tata bangunan laboratorium seharusnya mengikuti berbagai aturan yang dikembangkan baik oleh lembaga internasional atau pemerintah. Beberapa lembaga internasional Amerika yang mengembangkan standar pembangunan laboratorium diantaranya adalah American National Standards Institute (ANSI, antara lain ANSI Z-95 yang berhubungan dengan standar ventilasi laboratorium), National Fire Protection Association (NFPA), Building Officials Code Association (BOCA), American Society ofHeating, Refrigeration and Air Conditioning Engineers (ASHRAE, standar 110 untuk pengujian dan evaluasi ruang asam di laboratorium), National Elevtrical Code (NEC), serta American Chemical Society untuk green chemistry Institute

Kemendiknas (2010) laboratorium yang baik harus mampu menampung personal sesuai dengan kelayakannya. Idealnya, setiap personal yang melakukan praktikum di laboratorium harus memiliki ruang gerak seluas $\pm 2,5 \mathrm{~m}^{2}$ (termasuk area meja dan kursi), dengan tinggi langit-langit minimal 4 m. Ruang laboratorium yang sempit, selain menyebabkan personal sulit bergerak, juga sangat riskan apabila terjadi kecelakaan, karena akan menyulitkan dalam upaya penyelamatan diri. Selain harus memenuhi kriteria teknis bangunan, pencahayaan serta ventilasi udara harus juga diperhatikan. Udara di laboratorium harus senantiasa mengalir, sehingga udara segar selalu mengalir menggantikan udara laboratorium. Untuk mengantisipasi terjadinya kecelakaan, laboratorium IPA setidaknya memiliki dua pintu, yaitu pintu masuk dan pintu keluar.

Bangunan laboratorium IPA hendaknya dibangun di tempat yang agak jauh dari ruang kelas agar tidak mengkontaminasi lingkungan. Idealnya laboratorium IPA terpisah untuk setiap bidangnya (kimia/biologi, fisika), tetapi pada dasarnya setiap laboratorium IPA terdiri dari ruangruang praktikum (dapat menampung 35 personal/1 kelas), ruang persiapan laboran, ruang penyimpanan alat/bahan, ruang guru/intruktur pembimbing praktikum, serta ruang khusus yang diperlukan oleh setiap bidang (misalnya ruang timbang untuk lab kimia, ruang gelap/bengkel untuk lab fisika, dan ruang steril untuk lab biologi). Selain itu, toilet sangat penting berada di dekat laboratorium

Fasilitas keamanan sangat penting di laboratorium IPA. Dibandingkan dengan fasilitas lain, laboratorium IPA memiliki kekhasan dan permasalahan yang harus dihadapi, yaitu: 
a. laboratorium harus sangat lentur dan mudah menyesuaikan diri, karena sifat pekerjaan di laboratorium sudah dapat direncanakan.

b. Laboratorium IPA adalah tempat kegiatan peserta yang memiliki potensi berbahaya cukup tinggi dan dapat menyebabkan kondisi tidak aman bagi lingkungannya.

c. Laboratorium IPA yang ideal membutuhkan dana yang besar untuk membangun dan menggunakannya.

d. Laboratorium IPA seringkali ditempati oleh peralatan yang mahal.

4. Personil Laboratorium IPA

Personil laboratorium memegang peranan penting dalam penyelenggaraan kegiatan laboratorium. Personil yang tidak kompeten sudah pasti akan berdampak pada rendahnya kualitas kegiatan laboratorium, dan akan sangat beresiko terjadinya kecelakaan di laboratorium. Oleh karena itulah, maka personil laboratorium IPA harus memiliki kompetensi sesuai dengan kebutuhannya.

Selain kepala laboratorium yang bertanggungjawab terhadap semua kegiatan di laboratorium, personil lain di laboratorium IPA adalah koordinator praktikum, widyaiswara praktikum dan laboran. Widyaiswara praktikum merupakan ujung tombak kegiatan praktikum di laboratorium, sementara laboran berperan sebagai layanan sebelum selama, dan sesudah praktikum.

\section{PENUTUP}

\section{Simpulan}

Untuk mengembangkan laboratorium IPA di Balai Diklat Keagamaan Palembang di perlukan keahlian dalam menata bangunan dan ruang laboratorium, memerlukan personal yang kompeten serta keahlian untuk melaksanakan praktikum di Laboratorium IPA.

\section{Rekomendasi}

Disarankan agar penataan bangunan dan ruang, standarisasi keamanan, peralatan laboratorium dan personil laboratorium IPA yang berkompeten dibidangnya 


\section{DAFTAR PUSTAKA}

Kemendiknas.2010. Pengembangan Kompetensi Manajerial dan Organisasi Laboratorium. Kementerian Pendidikan Nasional Direktorat Jenderal Peningkatan Mutu Pendidik Dan Tenaga Kependidikan Direktorat Tenaga Kependidikan

Permendiknas RI No. 26 Tahun 2008 tentang Standar Tenaga laboratorium Sekolah/ Madrasah 